\title{
Priority Areas of Interaction Between Agribusiness and State
}

\section{Gavrilova Z.V.*}

Research Institute of Economics and Organization of the Agro-Industrial Complex of the Central Black Earth Region of the Russian Federation

Voronezh, Russia

e-mail: zoya0203@yandex.ru

Narolina Yu.V.

Research Institute of Economics and Organization of the Agro-Industrial Complex of the

Central Black Earth Region of the Russian Federation Voronezh, Russia

e-mail: narolinajv@yandex.ru

\begin{abstract}
The article discusses the theoretical and practical aspects of the interaction of the state and the agricultural business. It is shown that the intensification of cooperation of the state with the agrarian business contributes to the transformation of the agrarian structure, modernization of the agro-industrial complex. The specifics of interaction between the state and agricultural business are highlighted. The special importance of public-private partnership for solving urgent problems of the agro-industrial complex and rural territories was noted. The main directions of economic and social interaction between the state and agricultural business are presented. Positive examples of using cooperation between the state and agricultural entrepreneurship in the regions of Russia are discussed. The expediency of developing cooperation between agricultural consumer co-operatives and municipal authorities is justified.
\end{abstract}

Keywords - state, agribusiness, interaction, public-private collaboration, areas of interaction, social network.

\section{INTRODUCTION}

The effective functioning of the agro-industrial complex is due not only to the established key priorities, but also to the proper use of state and entrepreneurial resources necessary to achieve strategic goals. The important role in creating economic conditions for the steady growth of the agricultural economy is played by the effective interaction of agricultural business and the state. In the agro-industrial complex, the need to establish mutually beneficial relations between business and government is due to the following points:

- features of agriculture associated with a high level of risk (political, economic, environmental and climatic risks);

- the strategic economic importance of agribusiness, which requires the state support for the successful development;

\author{
Otinova M.E. \\ Research Institute of Economics and Organization of the \\ Agro-Industrial Complex of the Central Black Earth Region \\ of the Russian Federation \\ Voronezh, Russia \\ e-mail: 01maryina@gmail.com
}

\author{
Pashuta A.O. \\ Research Institute of Economics and Organization \\ of the Agro-Industrial Complex of the \\ Central Black Earth Region of the Russian Federation \\ e-mail: lina760@yandex.ru
}

- the lack of necessary financial resources and highly qualified personnel that resulted in the insufficient innovation activity of agribusiness;

- the ongoing decrepitude of rural areas, in particular the worn out social and engineering infra-structure of villages.

According to the international experience, the important condition for the successful implementation of large socially significant socio-economic investment programs and projects in rural areas is the effective interaction of the state and agrarian entrepreneurship, based on open and effective relations between large-size and medium-size business structures, farmers and the state.

The successful achievement of the strategic objectives related to ensuring food security, improving the quality of the rural population life, enhancing innovation processes in the agro-industrial complex is currently largely determined by the degree of use of state and business potentials. The consolidated efforts of the state and business sectors will create legal and economic conditions ensuring the sustainable growth of the agrarian economy.

The large agribusiness, with significant resources, is able to independently introduce innovations and improve its financial situation. On the contrary, the successful development of a small family agribusiness requires government support that does not limit financial assistance. Therefore, the issues of interaction between small agribusiness and self-government bodies of rural territories are of undoubtedly priority and practical relevance.

The subject of the research is the organizational and economic relations within the interaction of agrarian entrepreneurship and the state.

The theoretical and methodological basis of the research is the scientific works of domestic and foreign scientists, the 
experts on the organization of interaction between the agricultural business and the state, the regulatory legal acts of the Russian Federation.

The aim of the scientific article is to develop theoretical aspects and propose the main directions of development of interaction between the state and agricultural business.

The supplementing the theoretical provisions on the formation of interaction between agribusiness and the state, the conducting of factual analysis, the identifying of the effectiveness of existing areas of interaction in the agricultural sector, the substantiation of tools and the directions of the organizational and economic interaction of the state with the subjects of agricultural business, he contributing to the activation of innovative processes, the development of small agribusiness and the solution of socioenvironmental problems of rural areas has been carried out in order to achieve the goal of the study.

\section{LITERATURE REVIEW}

There are some attempts to understand and to characterize some elements of the relationship between government institutions and business in the works of such well-known founders of the theory of entrepreneurship as: R. Cantillon, Zh-B. Say, A. Smith, M. Weber, J. Schumpeter, A. Marshall, M. Friedman, G. Mins, G. Bowen, N. Chamberlain, X. Lampert, J. Stiglitz.

Theoretical, methodological and practical aspects of the business and the state interaction making are considered in the works of Bonnie Binu P., J. Jones, V. Varnavsky, M. Dasa, K. Dabat, A. Klimenko, Lena Perez V.G., Makherzhi A., Meiti A., Naumkina A., Perekrestova D., Ponusemi K., Sedrana P., Khairbekova A.U., Cherepukhina T., Shamkhalova F. and others [1-5].

Despite a significant number of studies and publications devoted to this topic, the formation and the use of optimal organizational forms as well as the economic and legal instruments of interaction between government agencies and agricultural business are still insufficiently substantiated at the practical and scientific-applied level. Theoretical studies concentrate on certain aspects. Therefore, there is a need to con-duct in-depth studies of the interaction of agricultural business and the states, taking into account both industrial structure and new environmental conditions.

Revealing the essence of the state and agribusiness interaction as a socio-economic concept, it should be borne in mind that the structure of the economy and the restructuring of the industry structure is obtained as a consequence of the main directions of use of resources available to the state. Also, targets were set, the achievement of which is stimulated by certain preferences.

Cooperation between the state and representatives of agricultural entrepreneurship is a system of organizational, legal, financial, economic and social relations between agricultural business and the state, aimed at achieving sustainable benchmarks that ensure a balanced socio-economic development of the agricultural economy and rural territories on the principles of mandatory, effective and voluntary
Considering the special place of agricultural entrepreneurship in meeting the needs of rural residents, it should be borne in mind that the performance of the state's socio-economic functions is not possible without an effective agricultural business.

The goal function the state and agricultural business interaction is based on systematization and balance of all partners interests. The expected result of interaction allows determining the level and scale of participation and contribution of each partner (fig. 1).

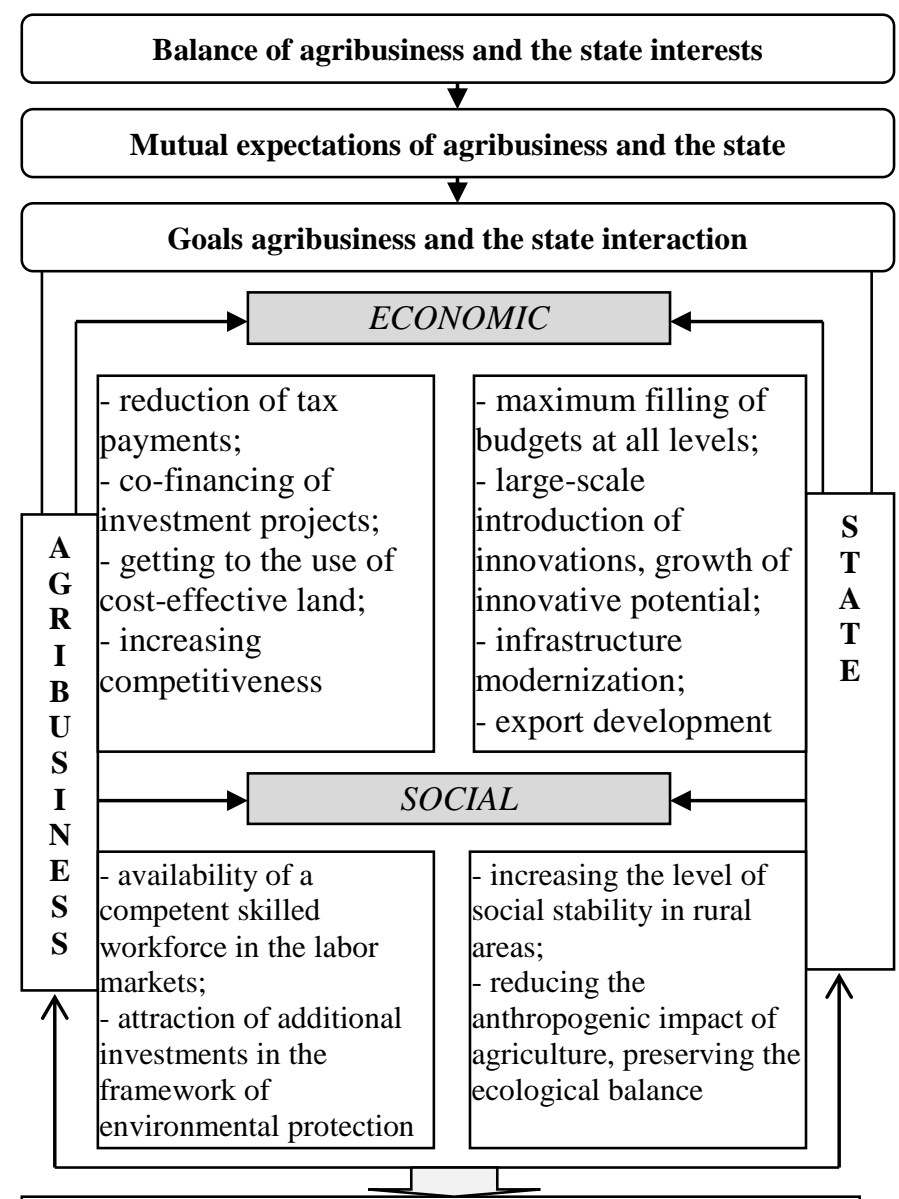

\section{The result of the interaction:}

- improving the quality of the rural population life;

- stable and sustainable functioning of agribusiness;

- digitalization and activation of innovation processes in the agroindustrial complex

Fig. 1. Balance of agribusiness and the state interests

In our view, the goal stated above in relation to the current situation of Russian society can be formulated as follows: preserving the integrity of the rural community as a single socio-economic system based on the creation of a rapidly growing rural economy aimed at improving the quality of life of the rural population and leveling differences compared to the urban population.

Effective economic management at the macro and micro levels is aimed at the effective functioning of all economic 
entities, which serves as a guideline for building stateagribusiness partnerships in the legal, economic and social spheres. The main purpose of the interaction of the agrarian business with the state is to gain access to the use of scientific, technical, financial, informational and other potentials that the state has. The use of public sector resources will allow the agricultural business to realize its main interest - maximizing income, expanding production [8-10].

The problems of rural areas in socio-economic development determine the state power goal ensuring a balance of interests of the rural population and agricultural business.

\section{RESULTS AND DISCUSSION}

The interaction of the state and the agrarian business entails the transformation of the agrarian structure, in particular, the sectoral structure of the agrarian economy changes, the production potential of the agro-industrial complex is modified, the diversity of activities in rural areas is expanded, and the ratio of large, medium and small businesses is changing. It is related to the fact that the state determines the mainstream of further development of the national economy and takes into account national interests.

A number of incentive preferences are created in order to achieve strategic priorities developed within the state agrarian policy. Thus there is a qualitative change of the participants interact.

The essential nature of the interaction between the state and the agrarian business is to promote the implementation of unattractive for the private sector economic, social and environmental projects at the expense of budget investments or the provision of tax benefits and subsidies.

The goals, the interests of agribusiness and the state determine the areas of interaction. We differentiate three main interaction areas: legitimate, economic and social. It is important to keep in mind that each area of cooperation has a different degree of involvement of participants in this relationship. For example, the needs of agricultural entrepreneurship and its goals are mainly to form legal interaction to promote their interests. Therefore, the state has an advantage in this area. In the economic sphere, the interests of agricultural business and the state are on the same competitive basis, since each participant receives the expected result. The state authorities are more interested in social cooperation with agricultural enterprises, so merchants can count on greater concessions from the state for the implementation of socially important projects.

The terms of interaction are determined during the development and coordination of the targets of regional and municipal economies based on a certain balance of interests of agribusiness and social goals within the framework of federal, regional and municipal policies.

At the same time, the population living in rural areas does not participate actively in building the interaction between the state and the farms. Although agribusiness in its activities seeks to meet the needs of citizens, and the state, implementing public policy, provides decent conditions for their livelihoods. In this regard, the task of building wellordered relations between interacting parties, namely, noting the responsibilities of the state and the agricultural business, is becoming increasingly important.

Considering the ever-increasing complexity of the relationship between society, the state and the agrarian business, the mechanism of their constructive interaction should be based, in our opinion, on the following initial settings:

- the consistency of the system of interests of all three sub-jects of interaction;

- social partnership and mutual social responsibility, i.e. agribusiness should be responsible to the population and to its employees within the territory of which it operates. The state should be responsible to the society and entrepreneurs respectively, providing conditions for proper life and conditions for effective functioning and sustainable development

- priority of public interests (Fig. 2).

The conducted analysis of the relationship system between business and the state in most Russian regions allowed to single out the following features:

1) the basis of cooperation is the exchange of resources. Agribusiness receives certain preferences, in particular, soft taxation terms and budget subsidies for investment projects. Regional governments expect business structures to adhere to social and eco-oriented behavior, in compliance with corporate social responsibility principles;

2) large-size agribusiness is actively involved in the development of a regional sectoral strategy; integrated programs of socio-economic development of the region.

It is important to note that the transformation of the Russian economy and the implementation of a socially oriented model have led to changes in the role and importance of agricultural business in solving socio-economic problems. At the same time, only large enterprises can build active partnerships with the state at present time.

At the moment public-private collaboration and concession agreement are currently being actively implemented in the housing and communal services areas, healthcare, and construction. It should be noted that in Russia, due to the lack of budgetary resources and the low financial sustainability of most agricultural enterprises, PPCs are practically not developed. This is due to the fact that specific spheres of application of the public-private collaboration mechanism in the agro-industrial complex and in rural areas have not been formed yet. Moreover, a private partner is more focused on projects with high capital productivity. Agriculture does not belong to this sphere.

Therefore, the state is forced to use additional incentives to attract private capital to increase the popularity of this form in the agro-industrial complex.

35.0 billion rubles have been set aside for the implementation of infrastructure projects in agriculture in 
2019. On the basis of PPP, two projects are being implemented in the Stavropol Territory: the greenhouse complex construction for the production of vegetable crops and the formation of a re-search and production cluster for the breeding and production of high-quality seeds of high-yielding varieties and the provision of Russian entrepreneurs.

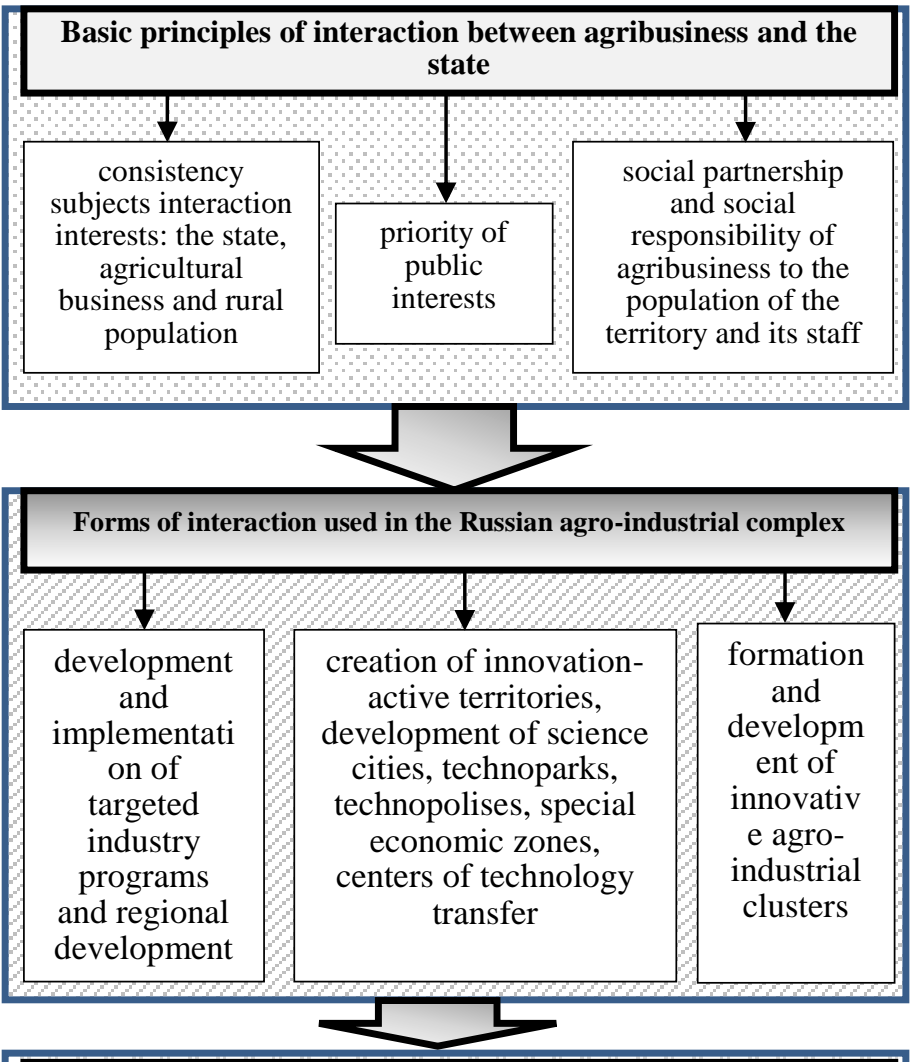

Priority areas of interaction agribusiness and government

\section{Economic cooperation:}

construction of grain elevators, vegetables-, fruit storage facilities, logistics distribution centers based on PPP;

- development of agroecotourism, participation of state media in the promotion of regional brands;

collaboration of state scientific institutions with entrepreneurial agricultural structures to develop innovations in the field of breeding and seed production;

- innovative and investment regional mega-projects on a PPP basis

\section{Social cooperation:}

- socialization of agribusiness: implementation of socially significant projects in rural areas;

- participation of agricultural business in personnel training, creation of educational clusters, joint training and research and experimental laboratories in large agricultural corporations that contribute to the development of innovative potential; - construction of waste processing plants and plants for utilization and processing of waste from livestock farms

Fig. 2. Directions of interaction between agribusiness and the state $[11,12]$.
A cluster for the production of marbled beef was established on the basis of LLC Zarechnoye in the Voronezh region on the basis of a public-private partnership in the agricultural sector. Consequently, the Voronezh Region is considered to be the largest producer and supplier of marbled beef in Russia.

In the Belgorod region, public-private partnership (PPP) is important tool for health care reform and tourism development. In the Republic of Mordovia, a feed mill was built on the basis of PPP, while the state's share was only $9 \%$, the remaining $91 \%$ of the funds has been invested by the entrepreneurial agricultural structures.

The actual direction of the development of PPP is the creation of tourist and recreational zones, the main functions of which are to preserve the historical and cultural heritage of our country. The recreational potential of agro and ecotourism is poorly realized. Currently, there are already successful practices of the use of the PPP mechanism in the tourism industry. Thus, in the Cheboksary, a tourist cluster "Ethnic Chuvashia" is being created, which includes the ethnoecological complex "Yasna" and the ethnocomplex "Amazonia" [11]. In the Lipetsk region on the basis of PPP tourist and recreational clusters "Yelets", "Dobry", "Shukhovsky" have been developed.

An effective tool for the agro-industrial complex innovative development is the creation of industrial parks, business incubators, and technological platforms. Thus, in the Oryol Region, the Green Grove industrial park is being built, organized on the basis of a public-private partnership.

Social cooperation at the municipal level is actively developing in the Belgorod region. For example, in the Rakityan district, Belgrankorm agricultural holding participates in the development of villages through the construction, reconstruction and renovation of social facilities (medical institutions, kindergartens, schools, cultural centers), the development of engineering infrastructure in rural localities (water, gas, new roads) [13].

In the Kursk region, farms, apart from production issues, also solve social problems by investing their own funds in the development of rural areas, the construction of cottage villages for their employees, building highways, etc.

The most relevant area of future environmental cooperation in the agro-industrial complex should be the PPC for the implementation of "green" projects, in particular the development and implementation of green production and green technologies. For example, these projects include projects for the construction and operation of waste disposal facilities for the livestock industry, taking into account the rapid development of animal husbandry in the Central black earth region [14]. The concession agreement is concluded in respect of such objects as vegetable storage facilities, grain elevators, logistics, wholesale distribution centers, etc.

In economic cooperation, attention should be paid to constructive interaction in the creation and implementation of a regional innovation strategy aimed at increasing the innovative activity of all business organizations, insuring 
innovative risks and stimulating agricultural science in the field of scientific and technological progress [15].

The effectiveness of the functioning of entrepreneurial structures in agriculture largely depends on the degree and forms of regulation of their development processes. In this regard, it is advisable to implement a policy of supporting family agribusiness at the district level, which includes a set of organizational and economic tools:

- holding coordination meetings, seminars, organizing advanced training courses, creating demonstration platforms for replicating good farming practices and introducing innovative technologies [16];

- creation of district credit cooperatives; multi-functional agricultural cooperatives, the development of relations be-tween small and large agribusiness;

- formation of a guarantee fund to support households and peasant farms at the expense of local budgets, which should be used for socio-economic development of rural areas and ensuring a high quality of life for rural people [17].

The implementation of these measures involves the accumulation of funds from the federal and regional budgets [18]. Municipal authorities and local governments can pursue an effective policy in cooperation with the entrepreneurs themselves, the financial institutions of the region (chambers of commerce, information and consulting centers, guarantee funds, banks, etc.) interested in forming harmonious mutually beneficial relations $[19,20]$.

Thus, the current trends in the socio-economic development of agribusiness show the need for effective economic tools that contribute to the development of effective interaction between business and the state (Fig. 3).

\section{CONCLUSION}

It is important to note that the transformation of the Russian economy and the implementation of a socially oriented model led to changes in the role and importance of the agrarian business in solving social and economic problems. At the same time, for the time being, only large-size business structures can build active partnerships with the state. Unfortunately, the importance of small business and farming in solving social and environmental problems in the countryside is not appreciated significantly. This is due in particular to the lack of financial support for obtaining budget funds and the implementation of joint projects, the lack of information about possible cooperation. The way out is to develop a cooperative-municipal partnership, namely the interaction of agricultural consumer cooperatives and municipal authorities.

The guarantees of property rights and freedom from regulation are the main problems that concern business structures.

The consolidation of entrepreneurs by interest groups is seemed to be necessary. It should not aim on short-term issues and narrow goals only, but it also should include long-term interests. Firstly, the executive branch should prioritize the long term development and inform entrepreneurs about the state policy strategy so that the latter formulate their position on this issue. Thus, a long-term alliance will be formed between agricultural entrepreneurship and the state.

Economic instruments used at various levels of interaction

\begin{tabular}{|c|}
\hline FEDERAL \\
\hline $\begin{array}{l}\text { - involvement of agribusiness entities in the } \\
\text { development of the territory through their } \\
\text { participation in the implementation of } \\
\text { comprehensive development programs; } \\
\text { - co-financing of programs; } \\
\text { - lobbying corporate interests for economic benefits }\end{array}$ \\
\hline$\square \quad L$ \\
\hline REGIONAL \\
\hline $\begin{array}{l}\text { - state order; } \\
\text { - implementation of certain state functions; } \\
\text { - competitions for grants and social projects; } \\
\text { - guarantee and investment funds; } \\
\text { - leveling the risks of changes in the terms of } \\
\text { financing; } \\
\text { - preferential taxation; } \\
\text { - provision of free consulting services }\end{array}$ \\
\hline$\ldots$ \\
\hline MUNICIPAL LOCAL \\
\hline $\begin{array}{l}\text { - identification of forms of agricultural } \\
\text { entrepreneurship that have the greatest effect on the } \\
\text { local economy; } \\
\text {-municipal loans, taxes, tariffs; } \\
\text { - participation in the development of the rural social } \\
\text { sphere; } \\
\text { - negative impact minimization on the environment and } \\
\text { ecology; } \\
\text { - conclusion of cooperation agreements with local } \\
\text { economic entities }\end{array}$ \\
\hline
\end{tabular}

Fig. 3. Directions of interaction between agribusiness and the state

In general, the formation of the effective interaction between agribusiness and the state will enhance the efficiency of functioning of all forms of agribusiness through the optimal use of the resource potential of territories ensuring the improvement of the management quality by improving the methods of strategic planning and forecasting and marketing research, resulting in the increase of the entrepreneurial activity in innovation and obtaining socially significant results for development of rural social infrastructure and the environment protection.

\section{References}

[1] K. Ponnusamy, P. Bonny Binoo, M.D. Das, "Impact of public private partnership model on women empowerment in agriculture", Indian J. of agricult. Sci., vol. 87, no. 5, pp. 613-617, 2017. 
[2] A. Mukherjee, A. Maity, "Public-private partnership for convergence of extension services in Indian agriculture", Current sci., vol. 109, no. 9, pp. 1557-1563, 2013.

[3] C.R. Dabat, V.H Luna Peres, “The Imperial Institute of Agriculture of Pernambuco- IIPA, 1859-1871: the failure of an innovative project of public private partnership", Revista Brasileira de Inovacao, vol. 14, no. 1, pp. 217-239, 2015.

[4] W. Chamberlain, W. Anseeuw, "Inclusive businesses in agriculture: Defining the concept and its complex an evolving partnership structures in the field", Land use policy, vol. 83, pp. 308-322, 2017.

[5] P. Sadran, Public-private partnership. Encyclopædia Britannica. Retrieved from: https://www.britannica.com/topic/public-privatepartnership.

[6] V.G. Varnavskii, A.V. Klimenko, V.A. Korokev, Public-private partnership: theory and practice. Moscow: National Univer. Higher school of Econ., 2010.

[7] A.V. Naumkin, Public-private partnership in modernizing agricultural sectors. Moscow: Sci. and inform. Product. and commercial center Voskhod-A, 2011.

[8] F. Shamhalov, Fundamentals of public administration theory. Moscow: Econ., 2003.

[9] N.V. Gorbacheva, "Evaluation of economic inequality in manufacturing public-private partnerships", St Petersburg univer. J. of econ. studies, vol. 34, no. 2, pp. 317-342, 2018.

[10] K. Druzhkov, V. Eremin, "Public-Private Partnership - an Actual Form of Implementation of Infrastructure Projects", Econ. and Mathemat. methods, vol. 54 no. 4, pp. 111-115, 2019.
[11] Creation of the tourist and recreational cluster "Ethnic Chuvashia". Official portal of the city of Cheboksary. Retrieved from: http://gov.cap.ru/SiteMap.aspx?gov_id=81 \&id= 1945810.

[12] M.Ye. Otinova, Z.V. Gavrilova, Mechanism of interaction between agricultural entrepreneurship and the state. Voronezh: NIIEOAPK, 2018.

[13] M.Ye. Otinova, Z.V. Gavrilova, "On the issue of the effectiveness of forms of business activity in the agro-industrial complex," Russ. entrepreneurship, vol. 19, no. 10, pp. 2969-2982, 2018.

[14] R.M. Sampaio, M.B. Machado Bonacelli, "Renewable Technologies: interaction between public policies and private initiative, from the Brazilian biodiesel production", Revista tecnologia e sociedade, vol. 14, no. 34, pp. 17-34, 2018.

[15] A.A.R. Ioris, "The Politics of Agribusiness and the Business of Sustainability", Sustainability, vol. 10, no. 5, p. 1648, 2018.

[16] S. Alarcon, P. Arias, "The public funding of innovation in agri-food businesses", Spanish J. of agricult. Res., vol. 16, no. 4, p. e0111, 2018.

[17] B. Mbuyisa, A. Leonard, "The role of ICT use in SMES towards poverty reduction: a systematic literature review", J. of int. development, vol. 29, no. 2, pp. 159-197, 2017.

[18] I. Shchetinina, M. Stenkina, "Interactions of subjects of agrarian and industrial complex in the conditions of digital economy", APK: Ekonomika, upravlenie, vol. 10, pp. 23-33, 2017.

[19] S.M. Gorlov, G.V. Minosyants, "The institutional government regulation framework of business activity in Russian agriculture", Terra Econ., vol. 10, no. 1-3, pp. 5-7, 2012.

[20] N.D. Levina, I.V. Palatkin, "Business-Incubator as the Institute of Supporting the Development of Business-Processes at Rural Areas under Conditions of Globalization", Ekonomika sel'skokhozyaistvennykh i pererabatyvayushchikh predpriyatii, vol. 12, pp. 27-30, 2015. 